\title{
FAMILIAL NEONATAL LEUKAEMIA
}

\author{
BY \\ W. A. B. CAMPBell, A. L. MACAFEE and W. G. WADE \\ From the Royal Belfast Hospital for Sick Children
}

(RECEIVED FOR PUBLICATION JUNE 19, 1961)

Recently there has been considerable discussion in the literature about possible genetic factors in the aetiology of leukaemia. These have been summarized and discussed by Steinberg (1960). All authorities agree that it is rare to find more than one case of leukaemia among the children of a family, although cases occurring in cousins, uncle and nephew, etc., are less unusual. An additional feature of interest in the family which we now report is the onset of the disease in the neonatal period in the affected children.

\section{Case 1}

James G. was born on September 24, 1960, in the Royal Maternity Hospital, Belfast, by normal delivery at full term, following an uneventful pregnancy. He weighed $8 \mathrm{lb} .1 \mathrm{oz}$. $(3,660 \mathrm{~g}$.) at birth. No abnormality was detected at birth, and the neonatal course was normal with no haemorrhage or other evidence of blood disease.

Because of the previous family history he was followed up at the Infant Clinic of the Royal Maternity Hospital. His progress was good for the first three weeks of life; from then on his mother noted that he did not gain weight, although he took his feeds well, breast-feeding with one complementary bottle feed daily. On November 14, 1960, when 7 weeks old, his haemoglobin was found to have fallen to $7.5 \mathrm{~g} . / 100 \mathrm{ml}$., and he was admitted to the Royal Belfast Hospital for Sick Children.

On admission his weight was 9 lb. (4,085 g.). Apart from pallor there were no abnormal physical signs; the liver was just palpable, the spleen could not be felt, and the regional lymph nodes were not enlarged. There was no bruising or purpura.

Further examination of the peripheral blood revealed a white cell count of 5,200 per c.mm. and a platelet count of 48,000 per c.mm. The differential white cell count was as follows: neutrophils $13 \%$, lymphocytes $65 \%$, mature monocytes $12 \%$, and immature monocytes $10 \%$. The immature monocytes were abnormal forms, but their relation to the monocytic series was confirmed by phase contrast studies kindly performed by Dr. J. M. Bridges.

A marrow sample, which was moderately cellular, was aspirated from the iliac crest. The film showed a heavy lymphocytic infiltration, but the more striking feature was the presence of a large proportion of monocytes in varying stages of differentiation (Fig. 1).

Many of the monocytic cells were mature with a normal nuclear cytoplasmic ratio. The cytoplasm of these mature forms often contained small discrete vacuoles (Fig. 2) which in unfixed preparation failed to stain with Scharlach $\mathbf{R}$.

The nuclei tended to infold but nucleoli and mitotic figures were not prominent. These cells were identical with those seen in the peripheral blood, and there was an occasional instance of erythrophagocytosis. While the more primitive cells showed a clear tendency to differentiate into monocytes it was often impossible to distinguish them from the myeloid series with certainty. There were very few myeloid forms present. Nucleated cells in the erythroid series were sparsely distributed but were normoblastic in type. Other investigations included a reticulocyte count which was less than $2 \%$ and a serum bilirubin level which was less than $0.2 \mathrm{mg}$./ $100 \mathrm{ml}$. The urinary amino acid chromatogram showed only a slight excess of taurine.

The diagnosis of a monocytic type of leukaemia having been made, a transfusion of $90 \mathrm{ml}$. of fresh blood was given, which raised the haemoglobin to $13.3 \mathrm{~g}$./ $100 \mathrm{ml}$. Additional therapy included prednisone, $9 \mathrm{mg}$. daily, and 'achromycin' (tetracycline) $200 \mathrm{mg}$. daily. He failed to show any clinical improvement, and the white cell, platelet and reticulocyte counts in the peripheral blood never increased. A second transfusion of $100 \mathrm{ml}$. of fresh blood was given on November 26, without any lasting effect. Enteritis and epistaxis supervened and the patient died on December 2, 1960.

Autopsy. This was performed by one of us (A.L.M.), and showed the body of a male infant weighing 3,350 $\mathrm{g}$. with generalized wasting. The skin was pale; a pressure sore was present on the sacrum. There was no evidence of mongolism or other congenital malformation.

The body cavities were normal. The heart was normally developed and showed no lesion. The lungs were congested and showed no collapse or pneumonic change. The liver weighed $130 \mathrm{~g}$. and had a smooth surface showing no obvious infiltrations externally or on section. The spleen weighed $9 \mathrm{~g}$. and appeared quite normal. The kidneys and adrenals together weighed $40 \mathrm{~g}$. and all appeared quite normal. The bladder and external genitalia were normal. The pancreas was normal. In the pelvic colon a $3 \mathrm{~cm}$. long portion of the 


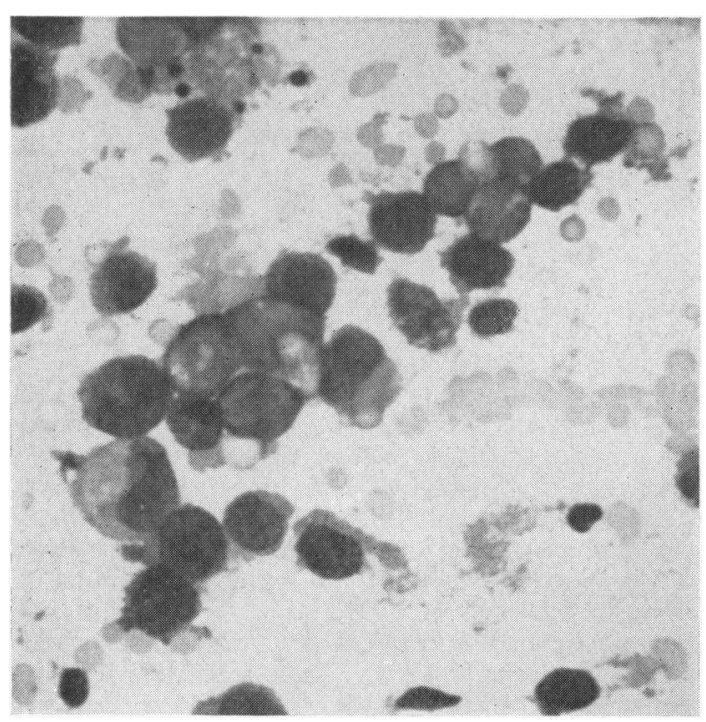

Fig. 1.-Bone marrow film of James G. to show abnormal monocytes. $($ Leishman $\times$ 440.)

gut wall was haemorrhagic and had a very thin fibrinous exudate covering it. There were no adhesions and no areas of perforation. The thyroid and parathyroid glands were normal. The tongue was normal. Lymph nodes from the left axilla and left groin were slightly enlarged having a uniform brown colour with soft consistency. The marrow was uniformly red in colour in vertebral bodies, ribs and femur. Permission to examine the brain was refused.

Histology. The heart was normal. The lungs showed some congestion and oedema, but no inflammatory or leukaemic infiltration. The liver was normal and there were no deposits of leukaemic cells. The spleen showed a little haemosiderosis and there was some erythrophagocytosis. No leukaemic infiltrates were noted. The kidneys were normal. The X-zone of the adrenal showed no regression, and the definitive cortex was developing normally. No signs of atrophy were noted. The pancreas was normal and there was no cystic change. The testis was normal and showed no leukaemic deposit. The thyroid was normal. The normal architecture of the lymph nodes was partially disturbed by a proliferation of primitive cells. These cells had an eosinophilic cytoplasm without granules and a centrally placed vesicular nucleus. The section of pelvic colon showed a severe haemorrhage extending through all the coats of the intestinal wall. There was no inflammatory or leukaemic infiltrate. The marrow was highly cellular, and there was a predominance of primitive cells which had lightly staining eosinophilic non-granular cytoplasm; this was fairly abundant. Some of these cells were binucleated and tri-nucleated. There were other primitive cells with less abundant cytoplasm and indented

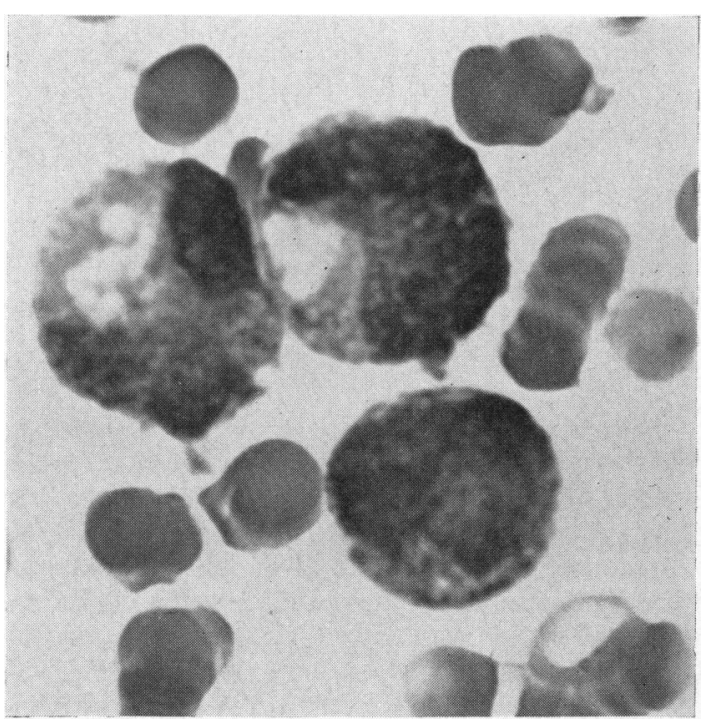

FIG. 2.-High power view of Fig. 1 to show vacuoles in the monocytes. $($ Leishman $\times 670$.)

nuclei and a few with cytoplasmic projections. The appearances suggested a proliferation of primitive stem cells with some maturation towards the myeloid and monocytic series. There were also many large phagocytic cells containing nuclear and red cell debris and some lipid (Fig. 3).

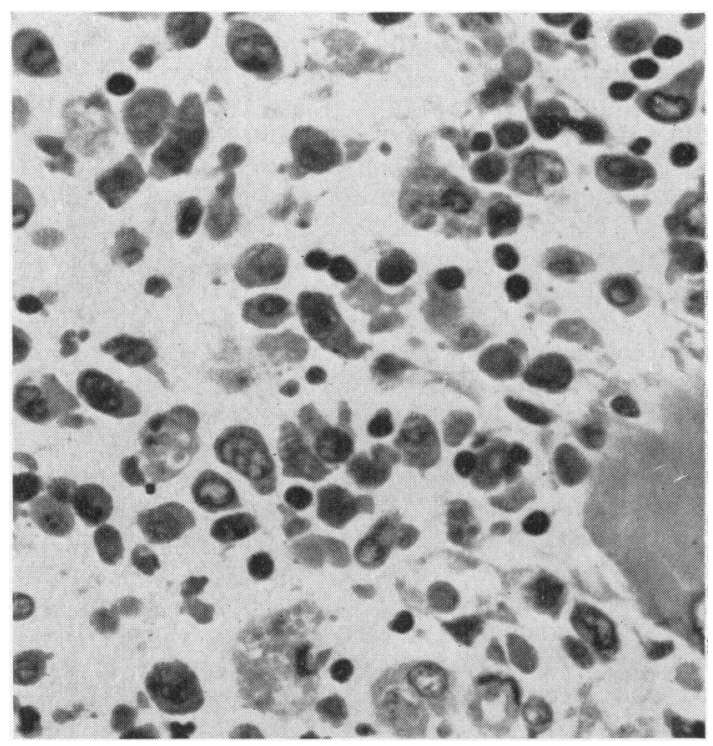

FIG 3.-This shows the bone marrow with an infiltration of primitive: cells and large macrophages which are showing erythrophagocytosis (H. and E. $\times$ 449.) 


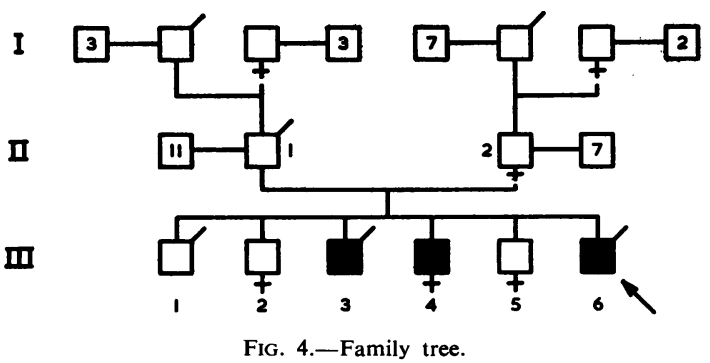

This picture was seen in the rib, femur and spinal marrow, and all were affected to a similar extent.

Anatomical Summary. Monomyeloid leukaemia with infiltrations in bone marrow and lymph nodes; haemorrhage into the wall of the pelvic colon.

\section{Family History}

Fig. 4 shows the history of the family so far. The parents are not related, and there have been no cases of leukaemia among the relatives shown. The possibility of exposure to irradiation has also been excluded. The blood groups of the immediate family are shown in the Table.

TABLE

\begin{tabular}{|c|c|c|c|c|}
\hline \multicolumn{2}{|c|}{ Family Member } & \multicolumn{3}{|c|}{ Blood Group } \\
\hline $\begin{array}{l}\text { J.G. } \\
\text { M.G. } \\
\text { T.G. } \\
\text { A.G. } \\
\text { J.G. } \\
\text { C.G. } \\
\text { M.G. } \\
\text { J.G. }\end{array}$ & $\begin{array}{l}\text { II: } 1 \\
\text { II: } 2 \\
\text { III: } 1 \\
\text { III: } 2 \\
\text { III: } 3 \\
\text { III: } 4 \\
\text { III: } 5 \\
\text { III: } 6\end{array}$ & $\begin{array}{l}\mathbf{A}_{1} \\
\mathbf{A}_{2} \\
\mathbf{O} \\
\mathbf{O} \\
\text { See } \\
\text { See } \\
\mathbf{A}_{1} \\
\mathbf{A}\end{array}$ & $\begin{array}{l}\mathrm{cDE} / \mathrm{cde} \\
\mathrm{CDe} / \mathrm{cde} \\
\mathrm{CDe} / \mathrm{cDE} \\
\text { cDE/cde } \\
\text { below } \\
\text { below } \\
\mathrm{CDe} / \mathrm{cDE} \\
\mathrm{CDe} / \mathrm{cde}\end{array}$ & $\begin{array}{l}\mathbf{R}_{2} \mathbf{r} \\
\mathbf{R}_{1} \mathbf{r} \\
\mathbf{R}_{1} \mathbf{R}_{2} \\
\mathbf{R}_{2} \mathbf{r} \\
\\
\mathbf{R}_{1} \mathbf{R}_{2} \\
\mathbf{R}_{1} \mathbf{r}\end{array}$ \\
\hline
\end{tabular}

No blood group incompatibility could be demonstrated between the serum of the mother (M.G.-II: 2) and the cells of the baby (J.G.-III: 6), but there was incompatibility with her husband's cells using the saline, albumin, papain and indirect Coombs' techniques, although a specific rhesus antibody could not be identified.

Of the two other siblings of James G. who also died, Joseph G. was born on November 30, 1955, and Catherine G. on October 24, 1957. The youngest of the surviving siblings, Moira G. was born on January 19, 1959. Joseph G. died at home at about 4 weeks of age. No details are available, but the cause of death was given as 'haemophilia', and his mother states that the clinical course was similar to that of the other two children who died subsequently.

\section{Case 2}

Catherine G. was admitted at the age of 3 weeks to the Ulster Hospital for Children and Women, under the care of Dr. Joan Logan, on November 1 1957. There was a history of difficulty in feeding, failure to thrive and marked apathy. Three days later she developed acute intestinal obstruction, and at operation volvulus of the small intestine was found and reduced. After operation she bled from the wound, vomited blood and passed blood-stained stools. An emergency transfusion of whole blood was administered.

After the blood transfusion, examination of the peripheral blood showed the haemoglobin to be $10.8 \mathrm{~g}$./ $100 \mathrm{ml}$., but the white cell and platelet counts were only $1,000 / \mathrm{c} . \mathrm{mm}$. and $24,000 / \mathrm{c} . \mathrm{mm}$. respectively. There were scarcely any leucocytes on the blood film and no leukaemic cells were identified.

A bone marrow sample showed a highly cellular picture which was dominated by a large cell type (Figs. 5 and 6 ).

These large cells were almost entirely filled by their nuclei which showed a marked tendency to infold and even to develop ring forms. The chromatin pattern was loosely arranged, but nucleoli and mitotic figures were scarce. The cytoplasm, which consisted only of a perinuclear rim, was deeply basophilic. A few small clusters of cytoplasmic granules were occasionally seen at one pole of the cell and these were usually eosinophilic.

Differentiation of these cells appeared to be in a myeloid direction but occasional vacuolated monocytes were seen. Erythrophagocytosis was a striking feature of this marrow. Only a few cells of the erythroid series. were present and these were normoblastic.

A comparison of the marrow pictures of this infant and of James G. showed only a slight morphological similarity, namely, in the presence of vacuolated monocytes which were common to both. These two cases may, however, represent variants of monomyelocytic leukaemia in which a different cell type predominated in each instance.

The other investigations in this case included a plasma protein picture. The total plasma proteins were only $3.6 \mathrm{~g} . / 100 \mathrm{ml}$. and the electrophoretic pattern showed a gross reduction in all protein fractions, except for the $\alpha_{1}$ and $\alpha_{2}$ globulins. In spite of intravenous prednisone, $5 \mathrm{mg}$. six-hourly, and tetracycline, $75 \mathrm{mg}$. daily, this patient died three days after the operation on November 20, 1957.

Autopsy. Autopsy, performed by Dr. J. B. Gibson, showed the body of a female infant weighing $3,500 \mathrm{~g}$. There was a recent abdominal operation incision, and numerous petechial haemorrhages were noted in the skin, especially around the head. The pleural, pericardial and peritoneal cavities contained large bloodstained effusions, and there were many petechial haemorrhages on the serous surfaces. The heart showed many small haemorrhages in the pericardium and a few under the endocardium. Development was normal and the valves and ventricles showed no lesion. The lungs were partly collapsed on account of the effusions. Some interstitial haemorrhages were also present. The liver weighed $210 \mathrm{~g}$. It felt firm and was dark red in colour. No definite infiltrates were seen. The gall-bladder contained very thick bile. The spleen was firm, and was dark in colour; no infiltrates were noted. The 


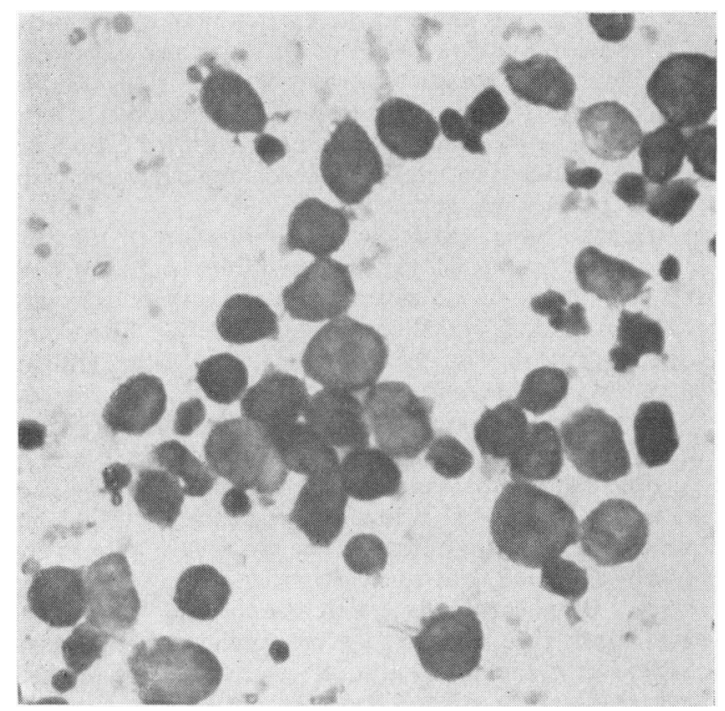

Fig. 5.-Bone marrow film of Catherine G. to show the abnormal myeloid cells. (Leishman $\times$ 440.)

pancreas and adrenals were normal. Stomach showed petechial haemorrhages in the mucosa. The small bowel mesentery was indurated and haemorrhagic. There was no recurrence of the volvulus, but much of the bowel was dark red, partly due to congestion and haemorrhage in the wall, and partly due to the blood in the lumen.

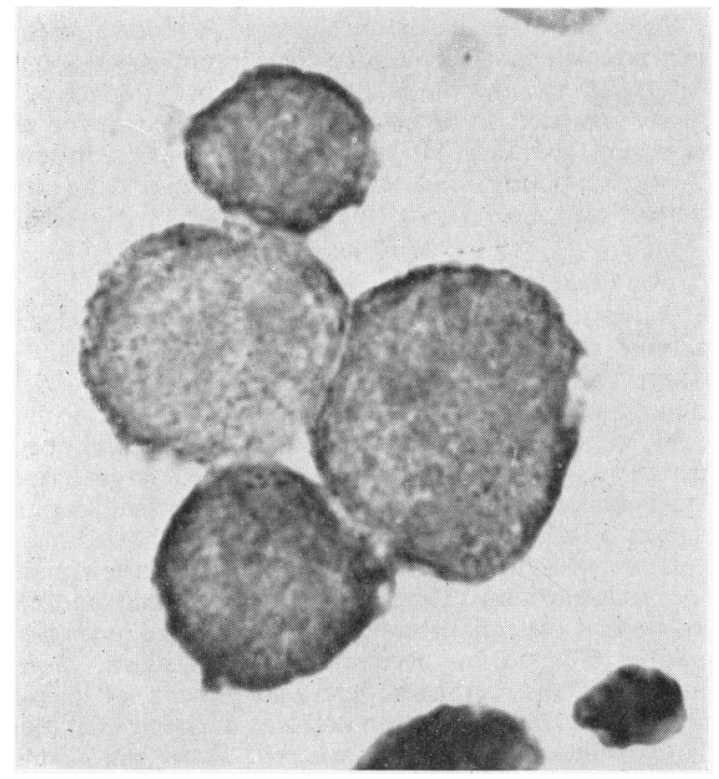

FIG. 6.-High power view of Fig. 5 to show the same cells. (Leishman $\times$ 760.)
Kidneys and genitalia were normal. Bone marrow of the sternum, vertebral column and the left femur was uniformly dark red in colour. The brain was not examined.

Histology. The heart was normal. The lungs showed a moderate degree of collapse throughout, without any infection. The spleen was congested. There were no abnormal infiltrations but there was slight erythrophagocytosis. Iron pigment was present in small quantities. The adrenals were normal. The abdominal lymph nodes had dilated sinuses and in them erythrophagocytosis was taking place. The pancreas showed a slight increase in interstitial fibrous tissue and a few of the acini were dilated into small cysts. The appearance was that of a very mild fibrocystic disease. The kidneys and thymus were normal. The sections from marrow from the distal end of femur, the vertebra and the rib had a similar abnormal microscopic appearance. The femoral marrow was the most active and there was a proliferation of the myeloid series with immature forms predominating, but small numbers of eosinophilic myelocytes were present. Cells of the monocytic series were scanty. Erythropoiesis was reduced, and erythrophagocytosis was noted.

Anatomical Summary. Early myeloid leukaemia, purpura, effusions in serous cavities. Early fibrocystic disease of pancreas; recent surgical operation for volvulus.

\section{Chromosome Studies}

Because of the unusual family history of two confirmed and one probable case of neonatal leukaemia, we consulted Dr. A. G. Baikie, of the Medical Research Council Unit, Western General Infirmary, Edinburgh. He kindly visited Belfast to examine the patient, James G., and took samples of blood and skin from him, and of skin from the parents, for chromosome studies. The results of these studies showed no abnormality in either the patient's peripheral blood or skin. The studies on the skin samples from the parents were also normal.

\section{Discussion}

It seems to be generally agreed that heredity plays a small part in the aetiology of human leukaemia, but there is some difference of opinion concerning the actual frequency with which familial cases occur. Videbaek (1958) found three familial cases out of 26 in one year, only one of these, however, concerned two siblings, the others being uncle and nephew and cousins respectively. In an earlier publication (Videbaek, 1947) he described an increased incidence of cancer, leukaemia and pernicious anaemia among the families of leukaemic patients. Anderson (1951) reported five cases of leukaemia among eight children; Reilly, Rapaport, Karr, Mills and Carpenter (1952) described three cases among eight children; and Johnson and Peters (1957) reported 
four siblings in a family. Other instances of leukaemia in siblings have been reported by Bieber (1951) and Revol, Millet and Thivollet (1954). Guasch (1954), reporting the replies received from 64 haematologists, listed 39 familial cases of leukaemia among a total of 8,586 cases, including grandparents, parents, uncles and aunts as well as siblings, and among these were 14 pairs of uniovular twins, in eight of which both twins were affected, in six only one twin, and in three pairs of binovular twins both were affected in two and only one in the other pair.

Other authors have not found a significant increase in the risk of leukaemia among members of the families of their patients. Amiotti (1953) found no increase in the incidence of malignant disease in the families of leukaemic children. Steinberg (1960) found no increase over the expected deaths from cancer in the families of 249 children with acute leukaemia and, after reviewing the literature, he concluded that there was, in general, no increased risk, but that, rarely, there might be a recessive inheritance. Morganti and Cresseri (1954) gave a detailed statistical analysis of the reports of familial leukaemia, and concluded that the published reports were so markedly selected that they gave an exaggerated impression of the familial character of leukaemia which was, in their opinion, a negligible factor in its aetiology. Bridges and Nelson (1961) found only three instances of leukaemia occurring more than once in a family among 182 cases seen at the Royal Victoria Hospital, Belfast; a father and son were concerned in one of these, and two cousins in each of the others. In none of the published reports of leukaemia occurring in siblings have we found any record of its appearance in the neonatal period, such as we have in the family reported here. Leukaemia is, in any case, rare in early infancy, most childhood cases arising between 2 and 5 years of age. According to the criteria of Bernhard, Gore and Kilby (1951) our cases could be included in the category of 'congenital' leukaemia, but as there was no definite evidence in any of the infants that the disease was actually present at birth we have preferred to follow Miller (1954) who adopted rather stricter criteria and was only able to find 23 cases in the literature, which he felt were definitely congenital.

However, it is interesting that the bone marrow in both our cases was myeloid rather than lymphoid in type. Miller recorded this as a striking feature distinguishing congenital leukaemia from acute leukaemia in older children, and suggested that this might be connected with the relative activity of the adrenal cortex in the immediate neonatal period.
It has also been the general experience that leukaemia in young infants differs from the disease in older children in its failure to respond to steroid therapy, as was our experience.

The cases which we report did not, however, show the skin lesions which have frequently been reported in congenital leukaemia (Oehme, Janssen and Hagitte, 1958; Kostitch-Joksitch, 1954; Grislain and Harrousseau, 1950), nor were there any associated congenital anomalies (Bernhard et al., 1951).

To our knowledge, this is the first instance of familial leukaemia in which chromosomal studies have been carried out on one of the affected siblings. The fact that these counts were normal was perhaps a little surprising in view of the chromosomal abnormality reported in mongols who have an increased susceptibility to acute leukaemia and in some cases of chronic myeloid leukaemia (Nowell and Hungerford, 1960; Baikie, Court-Brown, Buckton, Harnden, Jacobs and Tough, 1960).

\section{Summary}

A family is reported in which there have been one probable and two confirmed cases of neonatal leukaemia. It is believed that this is the first recorded instance of familial leukaemia presenting in the neonatal period.

Chromosome studies in this family did not reveal any abnormality, such as has been found in some cases of non-familial leukaemia.

Our thanks are due to Dr. A. G. Baikie and his colleagues Miss P. A. Jacobs, Miss I. M. Tough and Dr. D. G. Harnden for making chromosome counts. We are grateful to Dr. Florence McKeown for her assistance with the histological material, and to Dr. Joan Logan for permission to include clinical details of her patient. Our thanks are also due to Mr. D. Mehaffey for the photography.

\section{REFERENCES}

Amiotti, P. L. (1953). Sulla incidenza dei tumori nei familiari di bambini leucemici. Minerva pediat. (Torino), $5,449$.

Anderson, R. C. (1951). Familial leukemia. A.M.A. Amer. J. Dis. Child., 81, 313.

Baikie, A. G., Court-Brown, W. E., Buckton, K. E., Harnden, D. G., Jacobs, P. A and Tough, I. M. (1960). A possible specific chromosome abnormality in human chronic myeloid leukaemia. chromosome abnormality in

Bernhard, W. G., Gore, I. and Kilby, R. A. (1951). Congenital leukemia. Blood, 6, 990.

Bieber, A. (1951). Sopra un caso di emopatia (leucemia linpatica) in una coppia di gemelli bicori (falsi gemelli). Riv. Clin. pediat., 49, 161 .

Bridges, J. M. and Nelson, M. G. (1961). Familial leukaemia. Acta haemat., 26, 246

Grislain, J. R. and Harrousseau, H. (1950). Les leucémies aiguës 'congénitales' du nouveau-né. Nourisson, 38, 270.

Guasch, J. (1954). Hérédité des leucémies. Sang, 25, 384.

Johnson, M. J. E. and Peters, C. H. (1957). Four cases of leukemia reported in one South Dakota family. J. Indiana med. Ass., 50, 206. 
Kostitch-Joksitch, S. A. (1954). Leucémie congénitale du type parahémocytoblastique avec manifestations cutanées chez un nouveau-né. Sang, 25, 505.

Miller, F. (1954). Angeborene Leukämie. Virchows Arch. path. Anat., 326, 73.

Morganti, G. and Cresseri, A. (1954). Nouvelles recherches génétiques sur les leucémies. Sang, 25, 421.

Nowell, P. C. and Hungerford, D. A. (1960). A minute chromosome in human chronic granulocytic leukemia. Science, 132, 1497.

Oehme, J., Janssen, W. and Hagitte, C. (1958). Leukämie im Kindesalter. Thieme, Stuttgart.

Reilly, E. B., Rapaport, S. I., Karr, N. W., Mills, H. and Carpenter, G. E. (1952). Familial chronic lymphatic leukemia. Arch. intern. Med., $90,87$.

Revol, L., Millet, C. and Thivollet (1954). A propos de l'étiologie de la leucose aiguë. Sang, 25, 825.

Steinberg, A. G. (1960). The genetics of acute leukemia in children.

Cancer, 13, 985. Heredity in Human Leukaemia and its Relationship to Cancer. Busck, Copenhagen.

(1958). Familial leukaemia. Acta path. microbiol. scand. $44,372$.

\section{Addendum}

Since this article was prepared, Mrs. G. has had another child, and we append a preliminary report on this child. Rhesus antibody 'Anti-E' was present to titre 1/8.

Rita G. Born December 19, 1961. Blood group: $\mathrm{O}: \mathrm{CDe} / \mathrm{cDE}\left(\mathrm{R}_{1} \mathbf{R}_{2}\right)$.
Cord blood findings: Coombs' test strongly positive; Hb 12.2 g. $/ 100 \mathrm{ml}$. (84\%); leucocytes, $4,500,65 \%$ lymphocytes; no blast cells; six normoblasts/100 white blood cells; platelets, 25,000 ; bilirubin, $0.9 \mathrm{mg} .100 \mathrm{ml}$.

Bone Marrow Biopsy. Two samples of marrow were aspirated from different sites and showed similar pictures. The marrow was very hypocellular, with only occasional normoblasts and myelocytes, many of which were abnormal.

Treatment. An exchange transfusion of $560 \mathrm{ml}$. was carried out five hours after birth, and the subsequent course has been uneventful as far as haemolytic disease is concerned.

However, the hypoplastic marrow, together with the low platelet count, leucopenia and poor normoblast response to haemolytic disease, strongly suggest that this child also has leukaemia in the 'pre-leukaemic' phase. We have, therefore, given a transfusion of foetal liver cells, kindly supplied by Dr. Kay of the Royal Marsden Hospital, in the hope that this may provide normal haemopoietic tissue, and that this may not be rejected by so young an infant. 